IZA DP No. 8334

Does the Link between Unemployment and Crime Depend on the Crime Level? A Quantile Regression Approach

Horst Entorf

Philip Sieger

July 2014 


\title{
Does the Link between Unemployment and Crime Depend on the Crime Level? A Quantile Regression Approach
}

\author{
Horst Entorf \\ Goethe-University Frankfurt am Main \\ and IZA \\ Philip Sieger \\ Goethe-University Frankfurt am Main \\ Discussion Paper No. 8334 \\ July 2014 \\ IZA \\ P.O. Box 7240 \\ 53072 Bonn \\ Germany \\ Phone: +49-228-3894-0 \\ Fax: +49-228-3894-180 \\ E-mail: iza@iza.org
}

\begin{abstract}
Any opinions expressed here are those of the author(s) and not those of IZA. Research published in this series may include views on policy, but the institute itself takes no institutional policy positions. The IZA research network is committed to the IZA Guiding Principles of Research Integrity.

The Institute for the Study of Labor (IZA) in Bonn is a local and virtual international research center and a place of communication between science, politics and business. IZA is an independent nonprofit organization supported by Deutsche Post Foundation. The center is associated with the University of Bonn and offers a stimulating research environment through its international network, workshops and conferences, data service, project support, research visits and doctoral program. IZA engages in (i) original and internationally competitive research in all fields of labor economics, (ii) development of policy concepts, and (iii) dissemination of research results and concepts to the interested public.
\end{abstract}

IZA Discussion Papers often represent preliminary work and are circulated to encourage discussion. Citation of such a paper should account for its provisional character. A revised version may be available directly from the author. 


\section{ABSTRACT}

\section{Does the Link between Unemployment and Crime Depend on the Crime Level? A Quantile Regression Approach}

Two alternative hypotheses - referred to as opportunity- and stigma-based behavior suggest that the relationship between unemployment and crime also depends on preexisting local crime levels. In order to analyze conjectured nonlinearities between both variables, we are using quantile regressions applied to German county panel data. While both conventional OLS and quantile regressions confirm the positive link between unemployment and crime for property crimes, results for assault differ with respect to the method of estimation. Whereas conventional mean regressions do not show any significant effect (which would confirm the usual result found for violent crimes in the literature), quantile regression uncovers that size and importance of the relationship are conditional on the crime rate: The partial effect is significantly positive for moderately low and median quantiles of local assault rates.

JEL Classification: C21, E24, C33

Keywords: unemployment, crime, quantile regression, market of offences

Corresponding author:

Horst Entorf

Goethe-University Frankfurt am Main

Faculty of Economics and Business Administration

Department of Applied Econometrics

Grüneburgplatz 1

RuW/PF 48

60323 Frankfurt am Main

Germany

E-mail: entorf@wiwi.uni-frankfurt.de 


\section{Introduction}

According to an annual survey on "Ängste der Deutschen" (i.e. a survey on the angst of German citizens, conducted by $R+V$ Versicherung, a German insurance company) the fear to become a victim of a criminal offense regularly ranks in the top list of fears amongst German citizens. In 2013, 24\% of the respondents stated that they were are afraid of becoming a victim of a criminal offense. Although there is considerable variation across states in a given year (from 36\% in Mecklenburg-West Pomerania to $20 \%$ in Brandenburg), there is remarkably little variation over the years of this century: in 2013 an all-time low was reached with $24 \%$, while the highest value was $33 \%$ in 2002 . This is in line with the fact that in Germany crime rates themselves have been stable (or rather declined slightly) between 2003 and 2013 (PKS ${ }^{1}$ 2003, 2013) but show considerable variation across states. In addition to being one of the major fears in Germany, criminal activity is associated with large costs. According to Entorf and Spengler (2002), estimates of costs of crime range between 4\% and 7\% of GDP in most industrialized countries. Another fear which most of the time even ranks among the top five is the fear of rising unemployment in Germany. This fear was expressed by roughly $50 \%$ of respondents in the early 2000s, increased to $68 \%$ in 2005 (when unemployment was particularly high in Germany with about 5 million registered unemployed), vanished from the top 7 fears in 2007 and 2008 but was again expressed by more than $60 \%$ in 2009 and 2010 (when the financial crises was expected to hit the German labor market). As with the fear of victimization, there is also large cross sectional variation in the fear of rising unemployment and in the unemployment rate itself. Reducing unemployment has ever since been the concern of policy makers for similar reasons as mentioned above for crime rates: rising unemployment is a major fear of people and unemployment is costly in various ways. The same rationale as the one for fighting crime rates should hence also operate when it comes to reducing unemployment.

In this paper we reconsider the complex link from unemployment to crime using Germany county panel data. The economic rationale why such a link might exist is the following: Declining labor market opportunities (which are manifested by an increasing unemployment rate) worsen legal income opportunities and therefore make crime more attractive. This idea was first formulized by Becker (1968). Other studies focusing on the unemployment-crime relationship are (among many others) Cantor and Land (1985), Young (1993), Levitt (2001, 2004), Raphael and Winter-Ebmer (2001), Gould et al. (2002), Edmark (2005), Öster and Agnell (2007), Lin (2008), Lastauskas and Tatsi (2013) and Sieger (2014). These studies differ with respect to various aspects: used estimation methods, the

\footnotetext{
${ }^{1}$ PKS is the acronym of Polizeiliche Kriminalstatistik, i.e. "Police Crime Statistics".
} 
time span and country under consideration and the conclusion drawn with respect to magnitude of the effect of unemployment on crime. Lin (2008, p. 414) summarizes the results in the following way: "In terms of empirical evidence, recent studies reach consensus that unemployment does have a positive, significant but only small effect on property crime, and no effect on violent crime."

We deviate from existing studies in that we examine whether the effect of unemployment on crime depends on the level of crime by applying quantile regression methods. This would allow the identification of nonlinear crime-unemployment profiles with, e.g., a high impact of unemployment on crime for low-crime regions and a low impact for high-crime regions. This particular pattern would be consistent with a hypothesis of opportunity-based behavior: Those who become unemployed in a low-crime area have higher incentives to commit a crime than those in high-crime regions, because they would face less prevention of potential victims and lower competition from other criminals than those in high-crime areas. However, there could also be the opposite nonlinear pattern which we call the stigma-based hypothesis: It predicts low marginal effects from increasing unemployment rates in low-crime areas, because here any potential detection bears a higher risk of stigma than in regions where criminal behavior is more common. These examples show that there are good reasons to have a deeper look at the unemployment-crime relationship using quantile regressions. Surprisingly, so far there is only evidence based on this technique in the criminological literature. To the best knowledge of the authors, the only contribution is Bandyopadhyay et al. (2011). Based on time-series evidence from 6 crime categories and 43 police force areas, they confirm that not only unemployment does increase crime but it does so more in high crime areas. Moreover, they find that the crime-reducing effect of higher detection rates is stronger in low-crime areas.

The quantile analysis conducted in this paper is based on a panel data set covering all 301 German Landkreise (counties) and all 111 urban municipalities (kreisfreie Städte) of the years 2005 to 2009 in Germany. The same source (German counties and urban municipalities) has recently also been used by Messner et al. (2013) and Lastauskas and Tatsi (2013).

The remainder of this paper is organized as follows: section 2 gives an overview over the determinants of crime and their theoretical background. The underlying dataset is described in detail in section 3 . Summary statistics for the most important variables are provided. Section 4 discusses the applied econometric methodology. In section 5 the results of the estimation are presented and discussed in detail. Potential caveats are described and possible solutions will be discussed. Section 6 finally concludes. 


\section{Factors of Crime}

\subsection{Economic Factors}

Legal income opportunities represent an important factor of crime. Speaking within the framework of Becker (1968), higher legal income should decrease criminal activity, because legal income represents part of the opportunity costs of conviction. Higher legal income prevents a potential offender from committing a crime because he fears losing the legal income. Everything else equal (probability of detection and conviction and illegal income opportunities) higher legal income is expected to decrease criminal activity. However, there is another channel through which legal income affects crime if one switches from a micro to a macro perspective. If average legal income in a certain region (as a German county) increases, the potential offender is on the one hand more likely to have a higher legal income himself on average, and hence he is less likely to commit a crime. On the other hand, a higher average legal income might also increase his illegal income opportunities, since now there is more income or wealth he can steal from. At least for property crime, a higher legal income on average could therefore also increase criminal activity: The potential offender can expect larger loot since people around him are richer. This would, everything else equal, increase the utility of committing a crime. The effect of disposable income is therefore ambiguous, since it influences the decision to commit a crime or not through different channels.

The potential channel through which unemployment affects the crime rate is already briefly mentioned above: Declining labor market opportunities (which are manifested by an increasing unemployment rate) worsen legal income opportunities and therefore make crime more attractive. In their influential paper, Raphael and Winter-Ebmer (2001, p.262) express this idea the following way: "Conceptualizing criminal activity as a form of employment that requires time and generates income, a 'rational offender' should compare returns to time use in legal and illegal activities and make decisions accordingly. Holding all else equal, the decrease in income and potential earnings associated with involuntary unemployment increases the relative returns to illegal activity." The idea of time allocation between legal and illegal activities and its influence on the decision whether or not to participate in criminal activities was formalized in a theoretical framework by Grogger (1998). As Raphael and Winter-Ebmer (2001) lay out, Grogger's model can be used to predict how unemployment affects criminal activity. For individuals who engage in both, criminal activity and legal work, the model predicts that unemployment increases time allocated to crime. For individuals who do not work in the legal job market but only commit crimes, an unemployment spell cannot affect the time allocated to criminal activity. For workers not committing crimes, the effect of an unemployment spell depends on whether the return to the first hour of criminal activity exceeds his reservation wage. Consumers whose 
reservation wage is rather high are unlikely to be pushed into crime by an unemployment spell. Consumers with comparably low reservation wages are more likely to be influenced by unemployment and might try to offset lost income by engaging in criminal activity. Thus, Grogger's model predicts that for two of four categories, an unemployment spell will increase time allocated to criminal activity (and thus increase the crime rate), while for the remaining two categories, there is no response to an unemployment spell. Applying the idea of the model to regional data, theory would predict that responses to changing unemployment rates should be smaller in regions with already high crime rates than in regions where crime rates are low (given that reservation wages are not prohibitively high).

\subsection{Deterrence, Demographics, Education, Urbanity}

Becker's (1968) seminal economic model of crime abstracts from some important features of the criminal's decision problem. Several other determinates of crime have been discussed in the literature besides the just discussed deterrence variables (as the probability of conviction or the severity of fines). One of these determinants is the age structure of society. As outlined by Farrington (1986) who focuses on the United Kingdom and the United States the age-crime curve usually has a peak at teenage years and declines afterwards, meaning that individuals are most crime-prone at young ages and less so when growing older. Grogger (1998, p. 756) also provides evidence for this phenomenon: "Thirty five percent of all Philadelphia males born in 1945 were arrested before the age of 18, and one-third of all Californian men born in 1956 were arrested between the ages of 18 and 30. The 1990 census counted 1.1 million persons in jail, the vast majority of whom were men in their twenties and thirties." (Grogger 1998, p. 756). Similar patters can be observed for Germany. Crime suspects aged 6 to 20 make up $26.1 \%$ of all crime suspects but only $13.7 \%$ of the population. The crime suspects aged 40 and above make up $32.4 \%$ of all crime suspects but $56.9 \%$ of the population (PKS 2009). Given the descriptive evidence and the mostly ${ }^{2}$ accepted empirical evidence from other studies (as, e.g. Freeman 1996) it seems imperative to include the age structure as a further control variable when it comes to explaining crime. One would expect a positive influence of the share of crime-prone aged people in the population on criminal activity. Besides the fact that people at their young ages tend to commit more crimes, they are also victimized more often (PKS 2009, Table 91). A large share of young people might therefore foster criminal activities in two ways: it increases the supply of criminals as well as the supply of victims.

\footnotetext{
${ }^{2}$ Levitt (1999) and Levitt (2004) argue that the age structure alone does only have a limiting influence on the evolution of crime rates. Given that the age structure is as important as usually assumed, there should not have been a decline in crime rates from 1995 to 2004 in the United States. Since this decline was observed despite a larger share of crime-prone aged people, he argues that the effect of age structure on crime is rather limited.
} 
Data from the German police statistics (PKS) show that non-German crime suspects make up 21.1\% of all crime suspects, although contributing only $8.7 \%$ to the total population (PKS 2009). ${ }^{3}$ Possible reasons for this huge overrepresentation are discussed in Albrecht (1997). He mentions, among other things, deprivation and control theories, which focus on problems of social integration and reduced opportunities to develop ties to conventional society. The reasons for the apparent overrepresentation of foreigners in criminal activity shall not be discussed here in detail, but the mere numbers give rise to the need to control for the composition of the regional population when explaining crime.

Overrepresentation of crime suspects can be observed for yet another demographic group: men. Inspection of the raw numbers tells the following story: in 2009, out of the 2.187 million crime suspects, 1.64 million were male. That equals a share of $75 \%$. Controlling for the gender composition of the respective county hence seems to be as important as controlling for the already discussed demographic variables. One would expect a higher share of males in a given region to increase the number of offenses ceteris paribus.

Another determinant of criminal behavior is education. Unfortunately, there is no comprehensive data on educational attainment of the German population at the county level. The only variable that covers education at the county level is the share of workers subject to social security contribution who have not completed a vocational training (sozialversicherungspflichtig Beschäftigte ohne abgeschlossene Berufsausbildung). This variable only covers the education of a certain group of people, namely those who are subject to social security contribution. The predicted influence of this variable on crime is therefore hard to determine: on the one hand, less educated people are expected to commit more crimes. One could therefore expect a positive influence of this variable on crime. On the other hand, a high share of workers subject to social security contribution who have not completed a vocational training means that there are good labor market opportunities even for rather unskilled workers. Under this interpretation, a higher share of such workers would have a negative effect on crime. Empirical evidence for this can e.g. be found in Gould et al. (2002).

The last determinant which shall be discussed in this section is population density. There exist several theories why population density might be an important determinant of crime. On the one hand, densely populated areas (which are usually large cities) feature a weaker net of social control (Glaeser and Sacerdote 1999). The anonymity of the city makes it easier for individuals to commit crimes, since the potential stigma given being caught is less severe. In addition, similar to the argument applied above

\footnotetext{
${ }^{3}$ Even after excluding those offenses which can only be committed by non-Germans (such as offenses against asylum law and alike), the numbers only go down to $19 \%$ (2003) and 19.4\% (2009) respectively (PKS 2009, p.105).
} 
to the age composition, a large population density makes a "match" between a criminal and a victim more likely. Criminals may also have greater access to the wealthy in urban areas. Glaeser and Sacerdote (1999, p. 227) also mention the possibility of criminals facing a lower probability of detection and arrest in urban areas and that urban areas themselves attract (or create) crime-prone individuals. These theoretical considerations are confirmed for the data set which is used in this analysis. The bivariate correlation between overall crime rates and population density is remarkably high with 0.63 . One would therefore again expect a positive impact of population density on crime rates.

\section{Data Description}

The empirical analysis is based on data covering all counties (Landkreise) and urban municipalities (kreisfreie Städte) in Germany. Landkreise usually include one or more moderate-sized cities, villages, and rural areas, whereas bigger cities are organized as a stand-alone community (kreisfreie Stadt). In the following, both urban municipalities and rural counties will be referred to as "the counties". 4 This section describes the variables used in the analysis in detail. Detailed summary statistics will be presented of the most important variables.

\subsection{The Dependent Variables}

The dependent variables used in this study are the crime rates in each county. Before defining the term "crime rates" we describe which offenses are going to be analyzed. These are burglary, auto theft, and assault. The exact definition of each offense is given in the following paragraph. These definitions are translated by the authors from the German "Strafgesetzbuch" (StGB), i.e. the German penal code 5 .

- Burglary (Wohnungseinbruchsdiebstahl), criminal offense according to $§ 244$ Abs. 1 Nr. 3 StGB: Committing a larcency, for which the burglar breaks into a flat, enters with a counterfeit key or hides within the flat.

- Auto theft (Diebstahl in/aus Kraftfahrzeugen), criminal offense according to §242 StGB: Theft means taking personal property without permission or consent from another person with the

\footnotetext{
${ }^{4}$ Messner et al. (2013) prefer to use the German word 'Kreise' when referring to these two types of geographicadministrative districts, because they differ from counties in the USA. They present an example: A large city such as Houston may be within a county with other large cities; however, in Germany Houston would be a stand-alone community kreisfreie Stadt, i.e. counted as county.

${ }^{5}$ The authors would like to point out that the translation covers the most important points of the respective paragraphs, but does not constitute a word-by-word translation. German speaking readers are referred to the original source.
} 
intention to illegally acquire it. Auto theft covers those cases where either a car was stolen or something was stolen out of the car.

- Assault (Körperverletzung), criminal offense according to §223-227, 229, 231 StGB: Physically abusing another person or damaging another person’s health (§223); assault using a weapon, especially a knife or other dangerous tools, or using a deceitful attack, or a group, or method to endanger the life of someone ( $\$ 224)$; assault resulting in: the loss of a limb, the sight of one or both eyes, hearing, speech, or the ability to procreate; or, the long-term distortion of such; or, state of sickness, paralysis, or mental illness (§226); assault resulting in death (§227); negligent assault ( $\$ 229)$; the participation in a fight or an attack by several perpetrators that resulted in the death of a person or in serious bodily harm $(\S 231)^{6}$.

"Crime rates" are defined as the so-called frequency ratio (Häufigkeitszahl) from the German police statistics. It is defined as the number of cases (for a given offense) reported to the police per 100,000 inhabitants. As is pointed out by the PKS (e.g. PKS 2003, p. 14), the explanatory power of the frequency ratio is limited by the fact that only part of the committed crimes are reported to the police and by the fact that illegal aliens, tourists and transients might also commit crimes but are not counted as inhabitants of Germany. However, the latter restriction is negligible: in 2009 out of the 2,187,217 crime suspects only 46,132 (or $2.11 \%$ ) were illegal aliens and $6,739(0.31 \%)$ were tourists and transients, adding up to only $2.42 \%$ of all crime suspects. A slightly broader perspective which in addition includes asylum seekers $(22,137$ or $1.01 \%)$ and stationed armed forces and their family members $(2,249$ or $0.1 \%)$ produces a share of $3.53 \%$ of all crime suspects. The second problem of unreported crimes is more severe, though it can be mitigated by using fixed-effect models (see below).

Table 1 presents descriptive statistics for the frequency ratio for burglary, auto theft and assault. It is apparent that there is a huge variation in the respective crime rates. The overall distribution of the frequency ratio for auto theft is display in Figure A3 (appendix). In this figure it is nicely visualized what can also be inferred from percentiles in Table 1: Although the maximum frequency ratio for auto theft is 2,437 (recorded in Bremen in 2007), the 95\% percentile is only 878.5 , with a median of only 246. The minimum is even as small as 20 , which was recorded in the county Forchheim (Bavaria) in 2008. Hence the distribution is heavily skewed. Moreover, the regional or geographical distribution (Figure A4, appendix, shows a north-south pattern with higher frequency ratios in the north. Urban municipalities, at least those in the south (Bavaria and Baden-Württemberg), do not stand out particularly from an eyeball inspection of the Figure A40.

\footnotetext{
${ }^{6}$ Translation taken from Entorf and Spengler (2000, p. 103).
} 
Table 1: Descriptive statistics of crime rates (frequency ratios) for various offenses

\begin{tabular}{l|ccc}
\hline Percentiles & Burglary & Auto theft & Assault \\
\hline $5 \%$ & 22 & 66.5 & 325 \\
$25 \%$ & 47 & 138.5 & 421 \\
$50 \%$ & 84 & 246 & 538.5 \\
$75 \%$ & 138.5 & 413 & 704 \\
$95 \%$ & 275 & 878.5 & 1094.5 \\
Minimum & 3 & 20 & 202 \\
Maximum & 605 & 2437 & 2108 \\
Mean & 105.05 & 325.68 & 597.06 \\
Standard Deviation & 79.19 & 274.18 & 242.45 \\
\hline
\end{tabular}

Note: Statistics based on the years 2003 to 2009 and all German counties and urban municipalities. Frequency ratio is the number of reported offenses per 100,000 inhabitants.

Similar patterns hold true for the frequency ratio of burglary. Here, too, we observe a heavily rightskewed distribution and an enormous variation. The minimum frequency ratio for burglary is only 3 (recorded in Hildburghausen, Thuringia, in 2008), with the 5\% percentile being as low as 22 . In contrast, the maximum frequency ratio of 605 (recorded for Cologne, North Rhine-Westphalia, in 2003 ) is about 200 times higher than the minimum. The distribution over the whole time period under consideration and the graphical visualization of the distribution in the year 2009 are displayed in Figure A1 (appendix) and Figure A2 (appendix) respectively. Noteworthy is the clustered appearance of burglaries in the north and the west, while the south-west does not exhibit high frequency ratios even in the urban municipalities.

Assault, with a minimum frequency ratio of 202 (recorded in the county Enzkreis, BadenWürttemberg, in 2003) and a maximum of 2,108 (recorded in the urban municipality of Neumünster, Schleswig-Holstein, in 2007), does not show as much variation as did the other offenses analyzed so far. The ratio of minimum to maximum is rather low with a ratio of 10 (compared to, e.g., a ratio of 100 for auto theft or even 200 for burglary). In addition, the distribution is rather symmetric compared to the other distributions (Figure A5, appendix). Urban municipalities are among the most affected counties related to assault. They clearly stand out in the geographical distribution of the year 2009 (Figure A6, appendix). Besides the urban municipalities, the city states Berlin, Bremen and Hamburg as well as the region around the city of Hannover and the Rhine-Ruhr metropolitan region show rather large frequency ratios. The contrast between the south and the north is less pronounced than it is for auto theft or street crime.

A possible objection to using crime rates at the county level is that criminals do not necessary live in the same county where they commit the crime. For the offenses under consideration, however, about 
$75 \%$ of criminals live either in the same city or at least the same county where they commit the crime (PKS 2009). Only exceptional offenses (e.g. against the asylum law) have much lower rates in this respect.

\subsection{Economic Explanatory Variables}

Table 2 shows descriptive statistics of explanatory economic variables. These are the unemployment rate and the net income of private households. As unemployment is the major variable of interest, it is important to know its exact definition. A naïve definition is to divide the number of unemployed persons by the total workforce. This raises the question who is counted as an unemployed person and which persons are considered to be in the workforce. According to the Sozialgesetzbuch 3 (SGB 3), i.e. the German Social Security Code, $\S 16$ Abs. 2 a person is to be considered unemployed if

- he or she is temporarily not in an employment relationship or works less than 15 hours per week,

- he or she is looking for an employment subject to social security contributions,

- he or she is at the disposal of the employment agency's placement effort,

- he or she has registered as being unemployed at the employment agency.

Having defined the number of unemployed one has to define which persons are considered to be in the workforce. In Germany there are two different ways the workforce is defined. The first one is based on all persons in a dependent civilian employment (abhängige zivile Erwerbspersonen). These are persons within an employment subject to social security contribution (including apprentices), public servants (without soldiers) and persons in employment incentive programs (like "1-Euro-Jobs"). The second definition is based on persons within any kind of civilian employment (alle zivilen Erwerbspersonen). This broader measure includes all persons in a dependent civilian employment and in addition all self-employed persons and helping family members. The unemployment rate as displayed in Table 2 refers to the second definition of the workforce and is hence based on the number of persons within any kind of civilian employment.

The unemployment rate varies considerable across German counties. The county with the lowest unemployment rate during the period under consideration is the county Eichstätt (Bavaria) with a rate of $1.6 \%$ (recorded in 2008). The county with the highest rate is the county Uecker-Randow (Mecklenburg-Western Pomerania) with a rate of 29.3\% (recorded in 2004). Figure A7 (appendix) shows the distribution of unemployment rates during the period under consideration. It is right-skewed with a peak at about $8 \%$. A considerable fraction of districts (more than 5\%) experienced 
unemployment rates higher than $20 \%$. Taking a look at the regional distribution of unemployment rates across German counties in the year 2009 (Figure A8, appendix) shows that even 19 years after Reunification, the new German states still lag behind in terms of labor market success. Except for some urban municipalities (especially in the Rhine-Ruhr metropolitan area) the counties with unemployment rates higher than $10 \%$ are almost exclusively located in East Germany. In addition, only very few counties in East Germany have an unemployment rate smaller than $7 \%$. The vast majority of counties with rates below 5\% are all found in the south (states of Bavaria and BadenWürttemberg), while in the rest of Germany rates vary from $5 \%$ to $10 \%$.

\section{Table 2: Descriptive statistics of economic variables}

\begin{tabular}{l|cc}
\hline Percentiles & Unemployment rate & Net income of private households \\
\hline $5 \%$ & 0.039 & 29907 \\
$25 \%$ & 0.061 & 34747 \\
$50 \%$ & 0.087 & 39650 \\
$75 \%$ & 0.130 & 43527 \\
$95 \%$ & 0.202 & 49845 \\
Minimum & 0.016 & 24545 \\
Maximum & 0.293 & 69030 \\
Mean & 0.100 & 39520 \\
Standard Deviation & 0.051 & 6289 \\
\hline
\end{tabular}

Note: Statistics based on the years 2003 to 2009 and all German counties and urban municipalities.

The variation in net income of private households is less pronounced than the variation in unemployment rates using the coefficient of variation as a measure of dispersion. The lowest net income was reported in Leipzig (Saxony) in 2003 with 24,545€, while the highest net income was reported in the county Starnberg (which is located in the periphery of Munich, Bavaria) in 2006. 50\% of households have a net income between $35,000 €$ and $44,000 €$ at their disposal. Only 5\% have less than $30,000 €$ and only $5 \%$ have more than $50,000 €$. As already mentioned, only in very few counties private households earn more than $50,000 €$.

\subsection{Other Explanatory Variables}

The share of workers subject to social security contribution without completed vocational training (median $=15.6 \%$, mean $=15.2 \%$; from here on referred to as the share of unskilled workers in the workforce) has been introduced as factor representing the prevailing level of education. However, as described above, it is not entirely clear whether this variable truly captures education or rather job opportunities for unskilled workers. By looking at the regional distribution of the shares of unskilled workers in the workforce in the year 2009 (not reported elsewhere) one can see that the share of 
unskilled workers in the workforce is low in the new federal states while high in the south-west and rather mixed in the rest of Germany. Thus, one could conclude that the share of unskilled workers in the workforce rather captures labor market opportunities for unskilled workers than educational attainment. In Baden-Württemberg, e.g., a lot of medium sized and small businesses are located, especially in the manufacturing trade. These businesses seem to offer jobs also to unskilled workers, whereas the economic situation in the new German states is generally less beneficial. The lowest share of unskilled workers (7.3\%) was reported in 2009 in the county Greiz (Thuringia), the highest share (30.6\%) was reported in 2009 in the county Tuttlingen (Baden-Württemberg).

Deterrence plays a crucial role in economic models of crime. The severity of the expected fine as well as the probability of being caught are examples for deterrence measures that influence the propensity of committing a crime. Measures frequently used in empirical analysis in order to capture these deterrence effects are the size of the police force (e.g. Levitt 1997, Lin 2008), the incarceration rate (Raphael and Winter-Ebmer 2001, Phillips and Land 2012), or the clear-up rate (Entorf and Spengler 2000). Although theory suggests that it is imperative to include a variable that measures some form of deterrence, some studies fall short of including them (e.g. Öster and Agell 2007, or Yearwood and Koinis 2009). Based on data availability, we follow Entorf and Spengler and use the clear-up rate as a measure of deterrence. The clear-up rate is defined (according to PKS 2009, p. 14) as the ratio of solved cases times 100 to cases known to the police (data source: PKS). If cases reported in the previous year are mostly solved in the current year, this might result in a clear-up rate larger than 100 (which indeed has happened in the period under consideration). Clear-up rates significantly differ by type of crime. Whereas average clear-up rates for burglary $(26.0 \%$, median $=23.2 \%)$ and car theft $(15.4 \%$, median $=12.8 \%)$ are rather low, it is $90.7 \%($ median $=91.2 \%)$ for assault.

The demographic structure plays a key role in explaining criminal behavior. The share of the population aged 15 to 24 (mean $=11.8 \%$, median $=11.7 \%$; from here on referred to as the youth population) ranges from $8.9 \%$ in the county of Greiz (Thuringia, recorded in 2009) to the urban municipality Greifswald (Mecklenburg-Western Pomerania, recorded in 2005) with 17.7\%. Turning to the share of the population aged 25 to 54 (referred to as the "active population", mean $=42.6 \%$, median $=42.4 \%$ ) one can observe a close-to-normal distribution with a slightly more pronounced right tail (maximum $=49.3 \%$, recorded in Heidelberg, minimum $=37.4 \%$, recorded in Lüchow-Dannenberg (Lower Saxony).

Population density, the share of males and the share of the foreign population complete the list of explanatory variables. Population density is defined as number of people living in a given area divided 
by area in square kilometers. In Germany, population density varies considerably from 37.59 in the county Mecklenburg-Kreilitz to 4,282.21 in Munich. The mean value of population density (512.34 inhabitants per square kilometer, median $=197.3$ ) does not convey much information about the "typical" county: more than $70 \%$ of all counties have a smaller population density than this mean, which is inflated by a small number of extremely densely populated areas. The county with the lowest share of males is Baden-Baden (Baden-Württemberg) with a share of $46.0 \%$ (recorded in 2004) while the county with the highest share is Aachen (North Rhine-Westphalia) with 51.5\% (recorded in 2009). $95 \%$ of all counties during the period under consideration have male shares less than $50 \%$, so in almost all counties there live more women than men ( mean $=49.0 \%$, median $=49,1 \%$ ). However, it turned out that the variation of males across counties and over time is rather low and highly collinear with other factors of the population structure such that we had to omit it from the econometric analysis. The share of the foreign population varies considerably across German counties. The lowest share of foreigners was recorded in Sömmerda (Thuringia) in the year 2007 with only $0.7 \%$ foreigners in the population, while the highest share of foreigners was recorded in Offenbach am Main (Hesse) in 2003 with more than $26 \%$ of the population being foreign. A look at the percentiles shows that there are many counties with rather low shares of foreigners $(50 \%$ have rates lower than $5.8 \%$; mean $=6.8 \%)$, while there are few counties with rather high shares of foreigners $(5 \%$ of the counties in the period under consideration have shares of foreigners in the population higher than $15 \%$ ).

\section{Methodology}

We want to analyze the link between unemployment and crime rates conditional on the prevailing level of crime. While mean regression delivers a single parameter estimate for the effect of unemployment on crime, quantile regression allows different impacts of unemployment on crime depending on the level of criminal activity. This is useful for several reasons. For instance, one might get an insignificant effect of unemployment on crime in mean regressions, while there is indeed a negative (and significant) effect of unemployment on crime for low-crime areas and a positive (and significant) effect for highcrime areas. In mean regressions these two effects would simply cancel out, leaving the researcher with the conclusion that unemployment does not affect crime, while there might be in fact a non-trivial relationship between the two. Moreover, as suggested by the Grogger (1998) model, it makes a difference whether a certain percentage change $\Delta \mathrm{u}^{*}$ of the unemployment rate hits a region with only few criminals, or a region with a large share of full-time criminals. Quantile regression can therefore be seen as a tool of deeper inspection of the results of the mean regression, a path that does not seem 
to have been pursued in the context of analyzing the relationship between crime and unemployment so far (with the notable exception of Bandyopadhyay et al. 2011).

\subsection{Methodology - Mean Regression}

The starting point for the empirical analysis is the following model specification for the dependence of crime on unemployment

$$
\text { (1) } \text { Crime }_{i, t}=\beta \text { Unemployment }_{i, t}+\gamma^{\prime} X_{i, t}+\tau_{t}+\varepsilon_{i, t}
$$

The coefficient of interest is $\beta$ which captures the effect of unemployment in year $t$ in county $i$ on crime in year $\mathrm{t}$ in county $\mathrm{i}$. The vector of parameters $\gamma$ captures the influence of other explanatory variables as demographic, economic or deterrence variables. The $\tau$ 's are time fixed effects and capture the influence of shocks on the crime rate which affect all counties in the same way. $\varepsilon_{i, t}$ denotes the error term.

This model specification suffers from unobserved heterogeneity (e.g. due to region-specific shares of unreported crimes) which would lead to inconsistent and biased OLS estimates. The problem can be tackled by utilizing the panel structure of the data. Panel data are superior to a pooled cross section in that the former allows the researcher to include so called unobserved effects (or individual fixed effects). They are able to capture all time invariant factors which influence the crime rate and are specific to a certain county. Rural areas for example might be very different from urban areas in many respects which do not change over time (especially not over a rather short time period as analyzed here). These factors not covered in the data set which are specific to a county but do not (or only slowly) change over time (as e.g. prevailing shares of undocumented crimes) can all be lumped together in the unobserved fixed effect. Their inclusion can therefore help to mitigate the problem of omitted variables (Wooldridge 2002, p. 247).

By including these fixed effects, the resulting regression equation reads as

(2) Crime $_{i, t}=\alpha_{i}+\beta$ Unemployment ${ }_{i, t}+\gamma^{\prime} X_{i, t}+\tau_{t}+u_{i, t}$

where $\alpha_{i}$ denotes the fixed effect for county $\mathrm{i}$ and $u_{i, t}$ is the new error term. Although the $\alpha_{i}$ 's are unobservable it is still possible to estimate the parameters of interest in equation (2) by subtracting the (over time) mean of each county from the respective observation (or, equivalently, by including county dummy variables). Denoting mean values by upper bars, the regression equation reads as

(3) Crime $_{i, t}-\overline{\operatorname{Crlme}}_{i}=\beta\left(\right.$ Unemp $\left._{i, t}-\overline{\operatorname{Unemp}}_{i}\right)+\gamma^{\prime}\left(X_{i, t}-\bar{X}_{i}\right)+\tau_{t}+u_{i, t}-\bar{u}_{i}$ 
Note that the unobserved effect $\alpha_{i}$ does not appear in equation (3) anymore, but the parameters are the same as in equation (2). It is hence possible to estimate the parameters of interest $\beta$ by applying OLS to equation (3).

This specification might still suffer from the potential problem that unemployment is not an exogenous variable in equation (3). This problem might require the use of instrumental variables and has been addressed elsewhere (see, e.g. Raphael and Winter-Ebmer, 2001, or Lin, 2008). Lastauskas and Tatsi (2013) and Sieger (2014) consider the endogeneity problem using German county data.

\subsection{Methodology - Quantile Regression}

Mean regression deals with estimating the conditional mean function. This function describes how the mean of the dependent variable changes with the vector of explanatory variables. The underlying assumption is that the error term in the regression equation has the same distribution independent of the values of the explanatory variable. However, there exists the possibility that the explanatory variables influence the conditional distribution of the dependent variable in many other ways: stretching one tail of the distribution, inducing multimodality or expanding its dispersion (Koenker and Hallock 2001, p. 143). Investigating these other possibilities might offer a more detailed view on the relationship between the dependent and the explanatory variables. In particular, it might shed light on the question whether the effect of unemployment on crime depends on the level of crime.

There are (at least) two alternative crime-unemployment profiles that are imaginable from a theoretical point of view:

i) A declining crime-unemployment profile, where the effect of unemployment on crime is high in low-crime areas and low in high-crime areas.

ii) An increasing crime-unemployment profile, where the effect of unemployment on crime is low in low-crime areas and high in high-crime areas.

These two different crime-unemployment profiles correspond to two different interpretations on how criminals react to the level of criminal activity. If one was to observe i), a declining crimeunemployment profile, this would give rise to what we call the opportunity-based behavior. It would also be in line with the Grogger (1998) model. Given criminal activity is low an increase in unemployment has a relatively large impact on crime, because the supply for crime is highly elastic if there are attractive and unprotected victims and only a few competitors. If there are only a few drug dealers in the street, becoming a drug dealer is more profitable than if there are already many drug dealers around. If there are only a few burglars around, trying to break into a house is more profitable 
(maybe also because people do not invest so much in crime-preventing equipment such as alarm and warning devices). If crime is already high, that means the "crime-market" is already rather saturated, engaging in criminal activities after becoming unemployed is not as attractive anymore. Hence the supply becomes inelastic and the effect of unemployment on crime would be lower or insignificant. At a first glance, the reasoning seems plausible for property crimes, but less so for violent crimes such as assault. However, also for violent crimes it makes a difference whether the marginal crime effect of a certain change of the unemployment rate $\Delta \mathrm{u}^{*}$ hits a neighborhood of less protected citizens in lowcrime areas or a region of already high crime rates where further increases become unlikely, in particular because more and more people have taken precautions and avoided risky places.

If one was to observe ii) instead, i.e. an increasing crime-unemployment profile, this would give rise to what we call the stigma-based behavior. Given criminal activity is low, getting unmasked as a criminal in case of detection places a high stigma on the person, since there would be only a few criminals, and he or she is one of them. Funk (2004) describes such stigma of a potential detection as a crime deterrent. Higher unemployment rates would hence not necessarily push someone into criminal activity, since the fear of the stigma prevents the potential offender from doing so. However, if there is already a lot of criminal activity, becoming a criminal does not bother him or her too much, since even after being detected he or she will not be seen as the "black sheep". A rise in unemployment would hence more easily push the person into criminal activity.

\subsubsection{Ordinary Quantile Regression}

It might come as a mild surprise that quantiles, although seeming to be inseparately linked to the operations of ordering and sorting, can also be defined via a simple optimization problem (Koenker and Hallock 2001, p. 145). Similarly to OLS, where estimation is based on minimizing a sum of squared residuals, quantile estimation is based on minimizing a sum of weighted absolute residuals. More precisely, estimating the conditional quantile function for quantile $\tau$ is achieved by solving the following minimization problem

(4) $\min _{\beta} \sum \rho_{\tau}\left(y_{i, t}-\xi\left(x_{i, t}, \beta\right)\right)$

where $\beta$ is the parameter of interest, $\rho_{\tau}(u)=[\tau \mathrm{I}\{\mathrm{u} \geq 0\}+(1-\tau) \mathrm{I}\{\mathrm{u}<0\}]|u|=u(\tau-\mathrm{I}\{u<0\})$ is the quantile loss function and $\xi\left(x_{i, t}, \beta\right)$ is some parametric function ${ }^{7}$. In a first step, the parametric

\footnotetext{
${ }^{7}$ I denotes the indicator function taking the value 1 if the expression in the cambered brackets is true and 0 otherwise.
} 
function will be a linear function of the explanatory variables and the parameters to be estimated, as the right hand side of regression equation (1).

\subsubsection{Quantile Regression with Fixed Effects}

The approach presented above might also suffer from the problem of unobserved heterogeneity. Following Koenker (2004) we consider the following model for the conditional quantile functions of the dependent variable of individual $i$ at time $t$ :

(5) $Q_{y_{i, t}}\left(\tau \mid x_{i, t}\right)=\alpha_{i}+x_{i, t}^{\prime} \beta(\tau)$

where the $\alpha_{i}$ again denotes the individual fixed effect, $x_{i, t}$ is a vector of explanatory variables and the $\tau$-dependent vector $\beta$ is the vector of parameters to be estimated. In order to estimate model (5) for several quantiles simultaneously, Koenker (2004) proposes solving the following:

(6) $\min _{(\alpha, \beta)} \sum_{k=1}^{q} \sum_{t=1}^{T} \sum_{i=1}^{n} \omega_{k} \rho_{\tau_{k}}\left(y_{i, t}-\alpha_{i}-x_{i, t}^{\prime} \beta\left(\tau_{k}\right)\right)$

or, if the number of individuals is large relative to the number of time periods, a penalized version of (6), which reads as

(7) $\min _{(\alpha, \beta)} \sum_{k=1}^{q} \sum_{t=1}^{T} \sum_{i=1}^{n} \omega_{k} \rho_{\tau_{k}}\left(y_{i, t}-\alpha_{i}-x_{i, t}^{\prime} \beta\left(\tau_{k}\right)\right)+\lambda \sum_{i=1}^{n}\left|\alpha_{i}\right|$

where the $\omega_{k}$ 's are weights which control the relative influence of the q quantiles $\left\{\tau_{1}, \ldots, \tau_{q}\right\}$ on the estimation of the $\alpha_{i}$ parameters (Koenker 2004, p. 77), $\rho_{\tau}(\cdot)$ is again the quantile loss function and $\lambda$ is a shrinkage parameter. For $\lambda \rightarrow 0$, one would obtain the fixed effect estimator based on optimizing (6), while for $\lambda \rightarrow \infty$ one would obtain an estimate of the model purged of the fixed effects (Koenker 2004, p. 78) ${ }^{8}$. A routine that implements this estimator (and variants of it) has been provided by Roger Koenker and Stefan Bache and is available for the statistical software package $R$. More recent work on fixed effects quantile regressions also deals with potential endogeneity of explanatory variables. The approach outlined in Harding and Lamarche (2009) tries to overcome this problem by extending the work of Chernozhukov and Hansen (2008) and developing an estimation technique which is able to control for unobserved heterogeneity on the one hand, but is also able to incorporate the idea of instrumental variables.

\footnotetext{
${ }^{8}$ If the shrinkage parameter goes to infinity, the estimated fixed effects have to approach zero in order to find a minimum of equation (7).
} 


\section{Estimation Results}

\subsection{Estimation Results - Mean Regressions}

Table 3 shows the results for the two mean regressions applied in this study. The dependent variable is the logarithm of the frequency ratio of the respective offense. OLS regressions include, besides the unemployment rate, the logarithm of the clear-up rate for the respective offense lagged by one period ${ }^{9}$, the logarithm of disposable income, the logarithm of population density, the share of foreigners, the share of the young population (aged younger than 15), the share of the youth population (aged 15 to 24), the share of the "active population" (aged 25 to 55), the share of unskilled workers and time dummies. The analysis covers the years from 2005 to 2009, although data are available from 2003 onwards. The reason for this is a major labor market reform (the so called "Hartz-Reform") which was implemented in 2005. This reform had led to a redefinition of unemployment: Most people who were receiving social welfare benefits (Sozialhilfe) before 2005 were counted as "employable" and therefore unemployed after 2005 (instead of being out-of-the-labor force before). In order to avoid that results may be affected by different ways of defining the unemployment rate the time period used for estimation was restricted to the years 2005 to 2009.

Table 3 displays the results of OLS and fixed effects mean regressions. The estimated parameters are to be interpreted as semi-elasticities: an increase of the unemployment rate by one unit (which is one percentage point in this case) increases criminal activity by $\beta \%$. Based on the naïve OLS regression, unemployment has a positive and significant effect on crime for burglary $(9.6 \%)$ and auto theft $(10.3 \%)$, and a negative but insignificant effect on assault $(-0.4 \%)$. These results are in line with previous findings from the literature: the unemployment rate usually has a significant positive effect on property crimes (here: burglary and auto theft) while only small or insignificant effects on violent crime (assault). However, the OLS specification does not take the panel structure into account, i.e. regional peculiarities such as locally high or low shares of unreported crimes or unobserved factors of urbanity are not taken into account. The fixed effect regression (column FE in Table 3) does include county fixed effects and is therefore able to control for unobserved heterogeneity across counties. ${ }^{10}$ Applying it does not change the result of insignificance of unemployment on assault, but the FE parameters on car theft and burglary differ substantially from the ones of OLS parameters: The effect

\footnotetext{
${ }^{9}$ Lagging the clear-up rate by one period is done in order to avoid the problem of simultaneity: if crime rates are high this might induce more effort by the police or more police spending which in turn will have an influence on the crime rate itself. By lagging the clear-up rate by one period this problem is at least mitigated.

${ }^{10}$ However, this comes at some costs. On inclusion of fixed effects all slowly varying or quasi time-invariant variables became highly collinear and completely insignificant. Hence share of foreigners, share of unskilled, and all other variables representing the population structure have been omitted from the fixed-effect specification.
} 
on auto theft becomes insignificant, and the estimated parameter on the link between burglary and unemployment has been reduced to 4.4 (recall that the median unemployment rate of counties is about $9 \%$, i.e. a minus one percentage point change would be equivalent to a $-11.1 \%$ change for a median county). ${ }^{11}$

Table 3: Results from the mean regression for the effect of unemployment on crime

\begin{tabular}{l|cc}
\hline Offense & OLS & FE \\
\hline Assault & -0.364 & 0.175 \\
& $(0.289)$ & $(0.382)$ \\
Burglary & $9.634^{* * *}$ & $4.432^{* * *}$ \\
& $(0.909)$ & $(1.493)$ \\
Auto theft & $10.319^{* * *}$ & -1.053 \\
& $(0.911)$ & $(0.851)$ \\
Number of observations & 1947 & 1947
\end{tabular}

Note: Cluster-robust standard errors in parenthesis. Dependent variable: log (frequency ratio). OLS regressions include $\log$ (clear-up rate) for the respective offense lagged by one period, $\log ($ disposable income), $\log$ of population density, share of foreigners, share of the young population, share of the youth population, share of the active population, share of unskilled workers and time dummies. Note that due to some regional reorganization some counties had to be excluded from the data set. FE regressions include log (clear-up rate) for the respective offense lagged by one period, log (disposable income) and time dummies. All regressions have been weighted by the county specific population. ${ }^{*}, * *$ and $* * *$ denote significance at the $10 \%, 5 \%$ and $1 \%$ level respectively.

\subsection{Estimation Results - Mean Regressions}

Table 4 gives an overview of the results for the ordinary quantile regression. Some interesting insights emerge from comparing the methods under consideration. While the estimated effect of an increase in the unemployment rate on crime rates for assault has been insignificant in the OLS regression (see Table 3), it is positive and significant in the ordinary quantile regression at least for low levels of crime (i.e. the $5 \%$ and $25 \%$ quantiles). In addition, the crime-unemployment profile is slightly decreasing (Figure A9 (appendix)). The downward slope is even more pronounced for the offenses burglary and auto theft (Figures A10 and A11, appendix), giving rise to the interpretation that agents take the opportunity of committing crime as a response to unemployment when the "supply" of crime is rather low and "tolerance" towards crime is still high (see also Ehrlich, 1996, who argues that tolerance towards crime represents the demand side of a market of offences). Moreover, OLS estimates are within the middle of the respective quantile regressions, supporting the apprehension that in the OLS regression the effects at different quantiles are simply averaged and do not reveal the full picture of

\footnotetext{
${ }^{11}$ Results by Sieger (2014) confirm significance (resp. insignificance) and sign of presented FE results using an IV approach.
} 
the crime-unemployment relationship (but note that mean and median results differ due to the skewed crime distribution).

\section{Table 4: Results from the ordinary quantile regression for the effect of unemployment on crime}

\begin{tabular}{l|ccccc}
\hline Offense & \multicolumn{5}{c}{ Quantiles } \\
& 0.05 & 0.25 & 0.5 & 0.75 & 0.95 \\
\hline Assault & $1.126^{*}$ & $0.947^{* * *}$ & 0.418 & 0.412 & -0.715 \\
& $(0.681)$ & $(0.307)$ & $(0.333)$ & $(0.392)$ & $(0.977)$ \\
Burglary & $15.185^{* * *}$ & $9.718^{* * *}$ & $7.491^{* * *}$ & $7.038^{* * *}$ & $5.924^{* * *}$ \\
& $(1.212)$ & $(0.885)$ & $(0.671)$ & $(0.960)$ & $(1.051)$ \\
Auto theft & $12.789 * * *$ & $9.835^{* * *}$ & $8.829 * * *$ & $8.579 * * *$ & $7.921 * * *$ \\
& $(1.619)$ & $(0.741)$ & $(0.689)$ & $(0.889)$ & $(1.631)$ \\
\hline
\end{tabular}

Note: Bootstrapped standard errors in parenthesis. Dependent variable: log (frequency ratio). All regressions are based on 1947 observations and include $\log$ (clear-up rate) for the respective offense lagged by one period, $\log$ (disposable income), $\log$ (population density) share of foreigners, share of the young population, share of the youth population, share of the adult population, share of unskilled workers and time dummies. *, $* *$ and $* * *$ denote significance at the $10 \%, 5 \%$ and $1 \%$ level respectively.

\section{Table 5: Results from quantile regression with fixed effects for the effect of unemployment on} crime

\begin{tabular}{lccccc}
\hline Offense & \multicolumn{5}{c}{ Quantiles } \\
& 0.05 & 0.25 & 0.5 & 0.75 & 0.95 \\
\hline Assault & 0.908 & $0.896^{* *}$ & $1.344^{* * *}$ & 0.980 & 0.388 \\
& $(0.570)$ & $(0.378)$ & $(0.432)$ & $(0.856)$ & $(1.610)$ \\
Burglary & $11.910^{* * *}$ & $10.990^{* * *}$ & $11.270^{* * *}$ & $11.318^{* * *}$ & $11.888^{* * *}$ \\
& $(1.297)$ & $(1.383)$ & $(1.363)$ & $(1.596)$ & $(1.418)$ \\
Auto theft & $12.416^{* * *}$ & $11.005^{* * *}$ & $11.706^{* * *}$ & $12.628^{* * *}$ & $14.434^{* * *}$ \\
& $(1.505)$ & $(1.330)$ & $(1.079)$ & $(1.560)$ & $(1.943)$ \\
\hline
\end{tabular}

Note: Bootstrapped standard errors in parenthesis. Dependent variable: $\log$ (frequency ratio). All regressions are based on 1947 observations and include log (clear-up rate) for the respective offense lagged by one period, log (disposable income and a linear time trend. $* * *$ and $* * *$ denote significance at the $10 \%, 5 \%$ and $1 \%$ level respectively.

Table 5 displays the results from quantile regression with fixed effects. The parameter estimates are in general comparable to those obtained from ordinary quantile regression, but the pattern of the unemployment-crime profile has changed, in particular for property crimes. The effect on burglary and auto theft is still significant for all quantiles, but results do not replicate the decreasing effect with particularly high responses within low-crime areas. Instead, quantile parameters exhibit a rather flat crime-unemployment profile which is neither favoring the stigma nor the[нв1] opportunity based behavior. The effect of unemployment on assault is significant for rather low-(25\%-quantile) and median-crime regions (50\%-quantile) and insignificance is confirmed for quantiles above $50 \%$. The lacking significance for high-crime areas is in line with the opportunity-based criminal behavior, but 
the FE approach does not confirm the strictly downward sloping effect found with ordinary quantile regressions. $^{12}$

\subsection{Further Results}

Tables 6 and 7 show results for the effects of the clear-up rate and the net income on crime, i.e. of further factors of the economics of crime model. In line with theoretical expectations, the log of the lagged clear-up rate is negative and significant for all but one model specification. The only exception is the fixed effects mean regression of assault. The effect of the clear-up rate for property crimes ranges between -0.15 and -0.30 . The much larger effect of a one percent change of the clear-up rate for assault can be explained by its relatively high median clear-up rate of $91 \%$ (which is only $13 \%$ for auto theft, and $23 \%$ for burglary) and its low variation across counties. The quartiles at $25 \%$ and $75 \%$ are $89 \%$ and $93 \%$ respectively (see Sieger 2014, for details on the descriptive statistics) such that a change by $1 \%$ (for instance, from a 90-percentile down to the 89.1-percentile) already represents a substantial change, in particular given that assault rates, in contrast to auto theft and burglary, do not show a high variation across counties (see above). ${ }^{13}$ So when interpreting and comparing parameter estimates it needs to be taken into account that increasing the clear-up rate for assault by one percent would be more difficult, less likely and perhaps also much more costly than increasing the clear-up rate for property crimes by such an amount.

As regards the structure of the quantile regressions estimates, Bandyopadhyay et al. (2011) report that the crime-reducing effect of higher detection rates is stronger in low-crime areas. This can be confirmed for assault and using ordinary quantile regressions (which is also applied by Bandyopadhyay et al) in Table 6, whereas for fixed-effects and property crimes there is no obvious quartile-specific pattern.

Results of net income are less uniform. The clearest empirical evidence has been revealed for assault, where all estimates confirm the hypothesis that better legal income opportunities are associated with lower crime rates. The same effect can be observed for the $25 \%$ - and $50 \%$-percentiles (but not for the $75 \%$-percentile) of ordinary quantile regressions for auto theft and burglary. However, quantile fixed effects, pooled OLS, as well as standard mean FE modelling do not confirm this result so that we cannot reach an unanimous conclusion with respect to the effect on property crimes.

\footnotetext{
${ }^{12}$ Sieger (2014) also presents some preliminary quantile FE IV estimates. However, results lack robustness and seem to be highly sensitive to the choice of specification such that we do not comment on them further in this paper.

${ }^{13}$ The respective $25 \%$ and $75 \%$ quartiles of auto theft and burglary are $8.1 \%$ and $20 \%$ as well as $15.6 \%$ and $33.9 \%$, respectively (Sieger 2014).
} 
Table 6: Results from pooled OLS and ordinary quantile regression

\begin{tabular}{|c|c|c|c|c|}
\hline \multirow{2}{*}{$\begin{array}{l}\text { Log(clear-up } \\
\text { rate), lag(-1) }\end{array}$} & & \multicolumn{3}{|c|}{ Quantiles } \\
\hline & POLS & 0.25 & 0.50 & 0.75 \\
\hline Assault & $-2.762^{* * *}(0.275)$ & $-2.305^{* * *}(0.367)$ & $-1.685^{* * *}(0.342)$ & $-1.590^{* * *}(0.465)$ \\
\hline Burglary & $-0.313^{* * *}(0.035)$ & $-0.274^{* * *}(0.053)$ & $-0.309^{* * *}(0.034)$ & $-0.299^{* * *}(0.028)$ \\
\hline Auto theft & $-0.201^{* * *}(0.027)$ & $-0.156^{* * *}(0.026)$ & $-0.184^{* * *}(0.027)$ & $-0.164^{* * *}(0.031)$ \\
\hline \multirow[t]{2}{*}{ Net income } & & \multicolumn{3}{|c|}{ Quantiles } \\
\hline & POLS & 0.25 & 0.50 & 0.75 \\
\hline Assault & $-1.265^{* * *}(0.079)$ & $-1.137^{* * * *}(0.089)$ & $-1.187^{* * *}(0.113)$ & $-1.118^{* * *}(0.099)$ \\
\hline Burglary & $-0.010(0.212)$ & $-0.729^{* * *}(0.239)$ & $-0.613^{* * *}(0.212)$ & $-0.269(0.226)$ \\
\hline Auto theft & $-0.007(0.233)$ & $-0.830^{* * *}(0.256)$ & $-0.717^{* * *}(0.271)$ & $-0.289(0.254)$ \\
\hline
\end{tabular}

Note: Cluster-robust (POLS) and bootstrapped standard errors in parenthesis. Dependent variable: log (frequency ratio). See Tables 4 and 5 for further details. *,** and *** denote significance at the $10 \%, 5 \%$ and $1 \%$ level respectively.

Table 7: Results from fixed effects means and quantile FE regressions

\begin{tabular}{lcccc}
\hline $\begin{array}{l}\text { Log(clear-up } \\
\text { rate), } \text { lag(-1) }\end{array}$ & FE & 0.25 & 0.50 & 0.75 \\
\hline Assault & $0.214(0.182)$ & $-3.919^{* * *}(0.393)$ & $-4.158^{* * *}(0.376)$ & $-4.437^{* * *}(0.586)$ \\
Burglary & $-0.091^{* * *}(0.025)$ & $-0.299^{* * *}(0.053)$ & $-0.395^{* * *}(0.052)$ & $-0.376^{* * *}(0.039)$ \\
Auto theft & $-0.040^{* * *}(0.011)$ & $-0.252^{* * *}(0.047)$ & $-0.245^{* * *}(0.038)$ & $-0.278^{* * *}(0.041)$ \\
\hline \multicolumn{5}{c}{} \\
\hline Net income \\
\multicolumn{5}{c}{} \\
FEssault & $-0.430(0.197)^{* *}$ & $-0.899^{* * *}(0.106)$ & $-0.777^{* * *}(0.112)$ & $-0.844^{* * *}(0.170)$ \\
Burglary & $-0.810(0.770)$ & $0.593(0.391)$ & $0.220(0.403)$ & $0.141(0.412)$ \\
Auto theft & $0.219(0.431)$ & $0.423(0.360)$ & $0.315(0.299)$ & $0.261(0.382)$ \\
\hline
\end{tabular}

Note: Cluster-robust (FE) and bootstrapped standard errors in parenthesis. Dependent variable: $\log$ (frequency ratio). See Tables 4 and 5 for further details. $*$, ** and *** denote significance at the $10 \%, 5 \%$ and $1 \%$ level respectively.

\section{Summary and Conclusions}

This paper uses regional panel data from more than 400 German counties and quantile regressions to study the effect of unemployment on crime. The contribution and main focus is to test the hypothesis that size and significance of the effect of unemployment on crime have to be considered conditional on the prevailing regional crime level. We present two conjectures about the non-linear pattern of the relationship between unemployment and crime. First, there could be a downward sloping crime- 
unemployment profile with a high marginal impact of unemployment on crime for low-crime regions when those who become unemployed would have relatively large opportunities to become criminals. Likewise potential criminals would face less crime prevention and precautions from potential victims than those in regions where crime is already more elevated. On the other hand, it might be just the fact that there are only a few criminals around which prevents criminal behavior, because unemployed people would be deterred by some stigma effect. This contrasts to a situation with many criminals in the neighborhood where acting illegally becomes more likely as many others or even peers already have criminal experience. Empirical results show that conventional mean regressions indeed produce misleading results. For instance, while simple OLS and FE regressions depict insignificant results for assault (which would confirm the usual result for violent crime found in the literature), quantile regressions reveal positive and significant effects for median- and low-crime regions. For property crimes ordinary quantile regressions are clearly indicating behavior in line with the opportunity-based approach. This finding has not been confirmed using quantile fixed effects, where the positive and significant parameter estimates do not vary much across quantiles. Future work should also be based on individual data in order to identify and better understand the complexity of incentives and activities of potential criminals in high- and low-crime regions. This paper reveals that the relationship between crime and unemployment is not yet quite well understood. 


\section{Appendix}

Figure A1: Distribution of frequency ratio burglary for the years 2003 to 2009

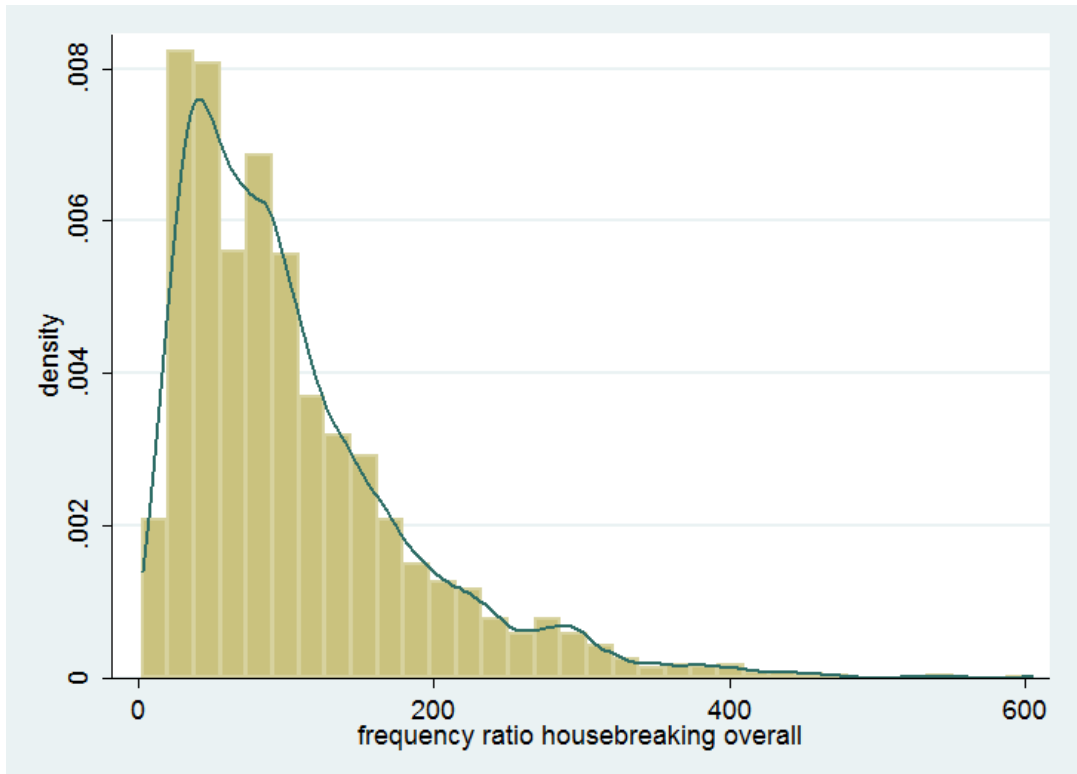

Figure A2: Regional distribution of frequency ratio burglary in the year 2009

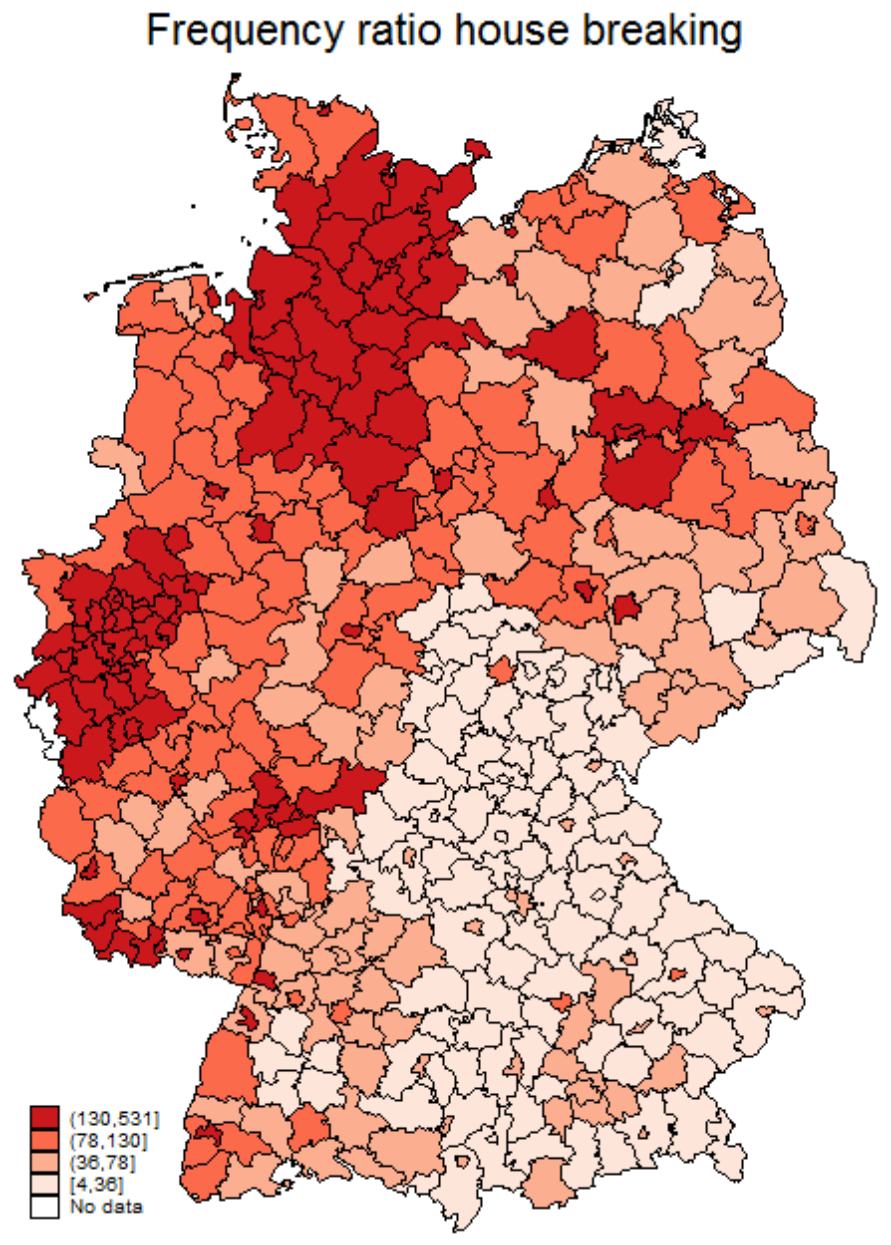


Figure A3: Distribution of frequency ratio auto theft for the years 2003 to 2009

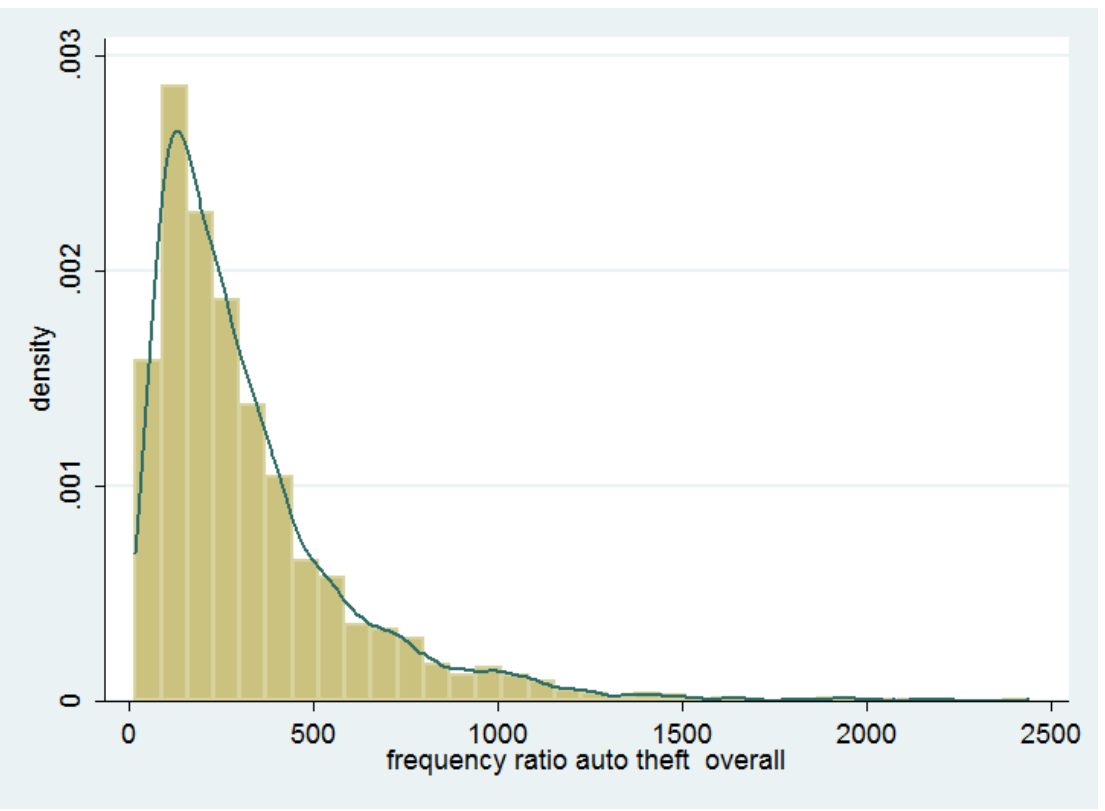

Figure A4: Regional distribution of frequency ratio auto theft in the year 2009

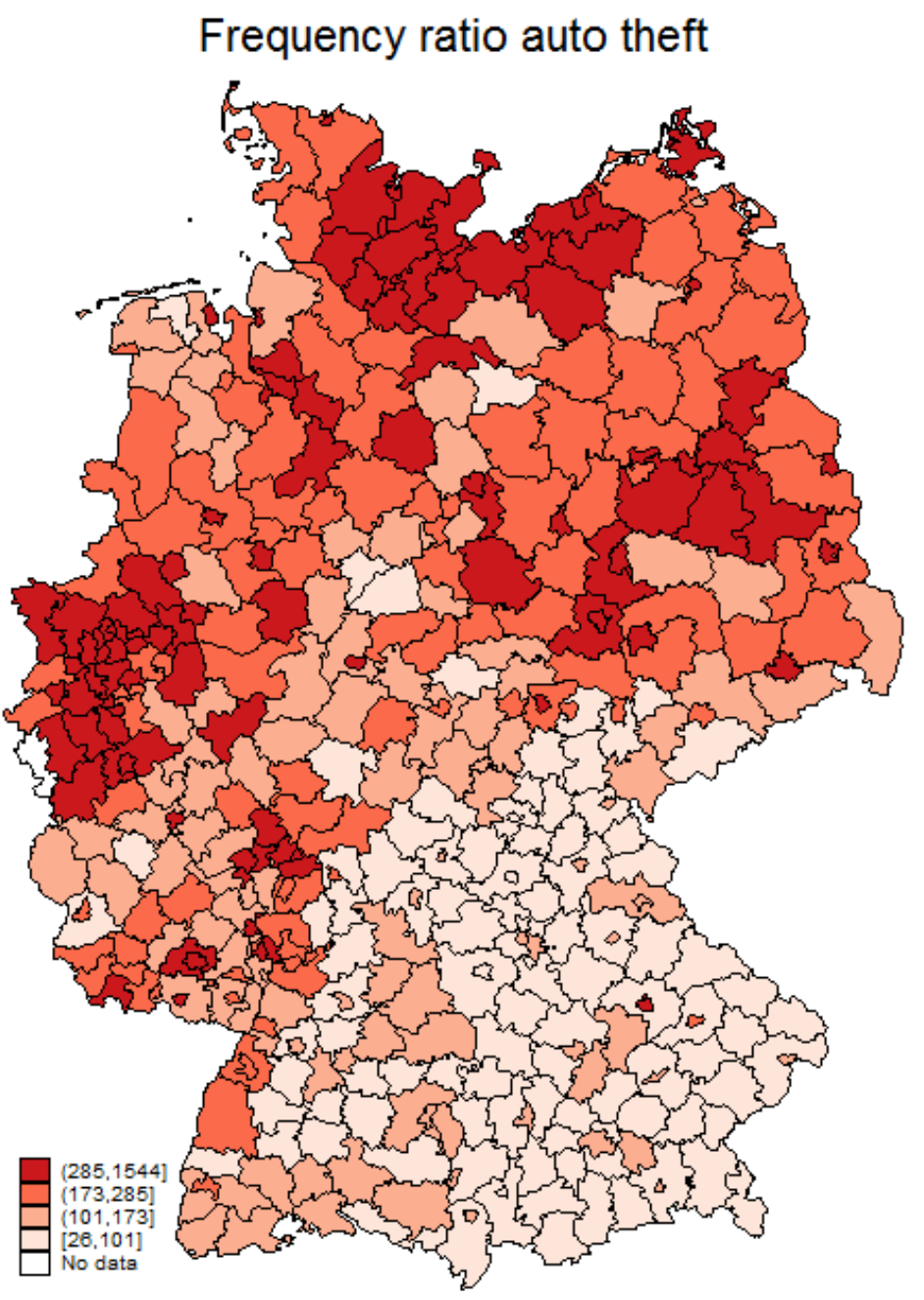


Figure A5: Distribution of frequency ratio assault for the years 2003 to 2009

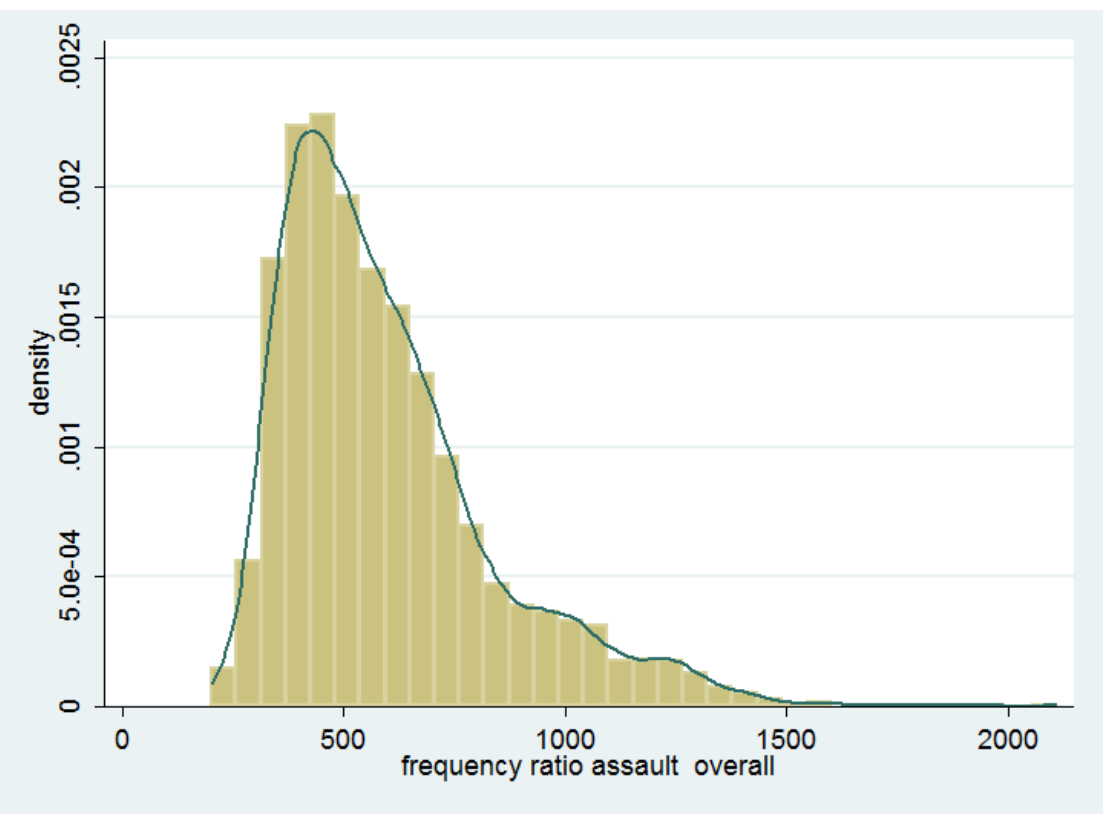

Figure A6: Regional distribution of frequency ratio assault in the year 2009

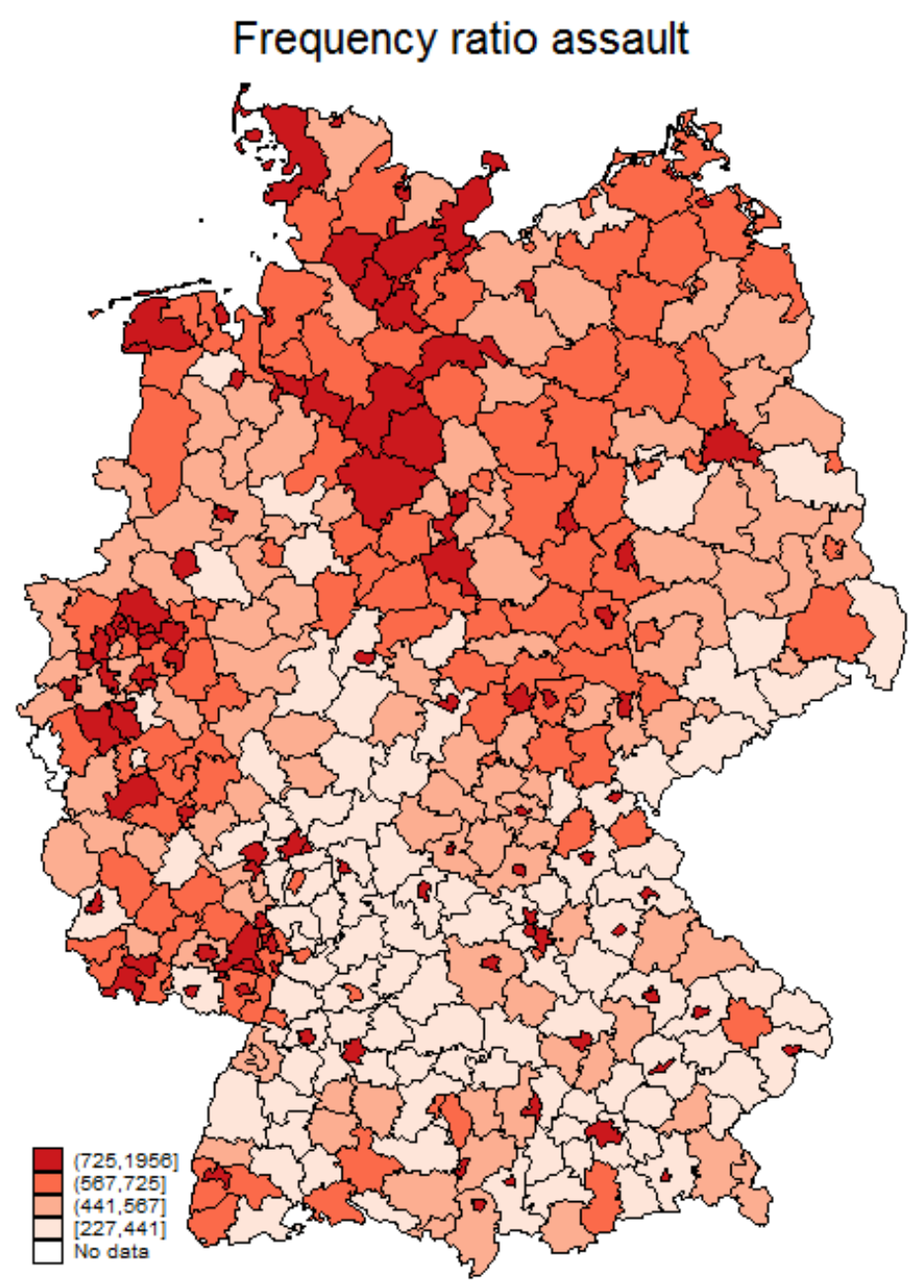


Figure A7: Distribution of unemployment rate for the years 2003 to 2009

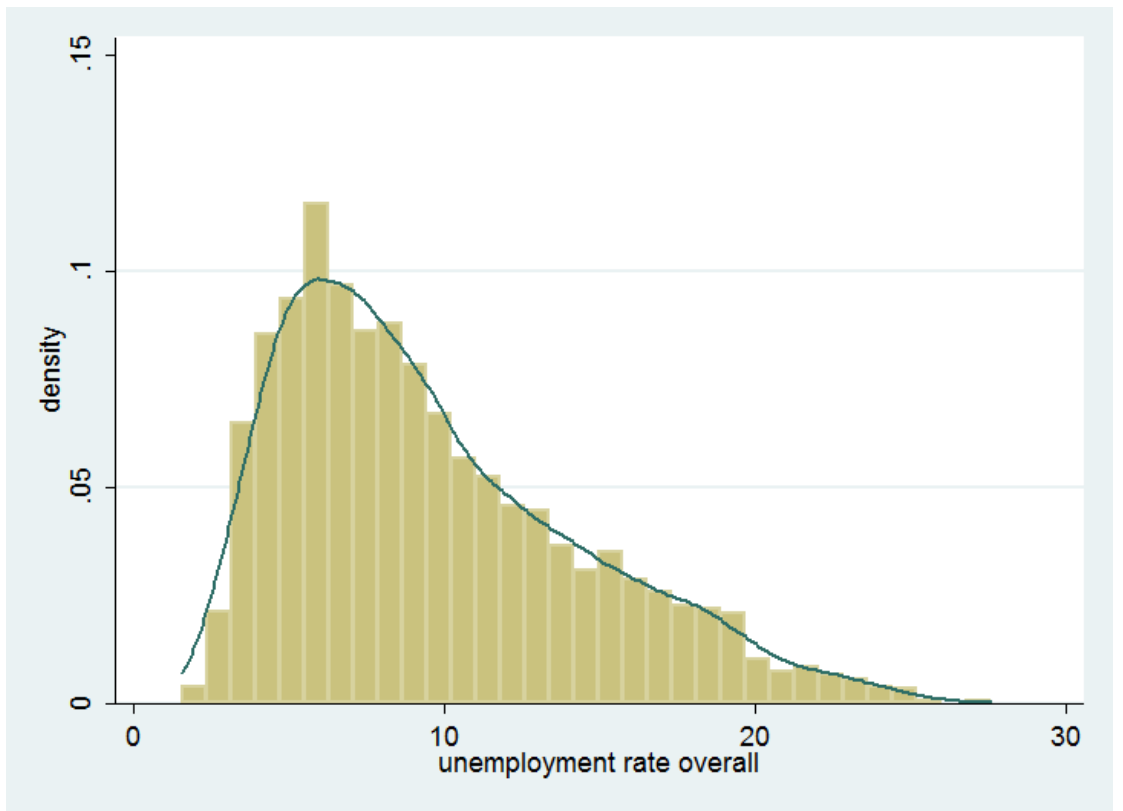

Figure A8: Regional distribution of unemployment rate in the year 2009

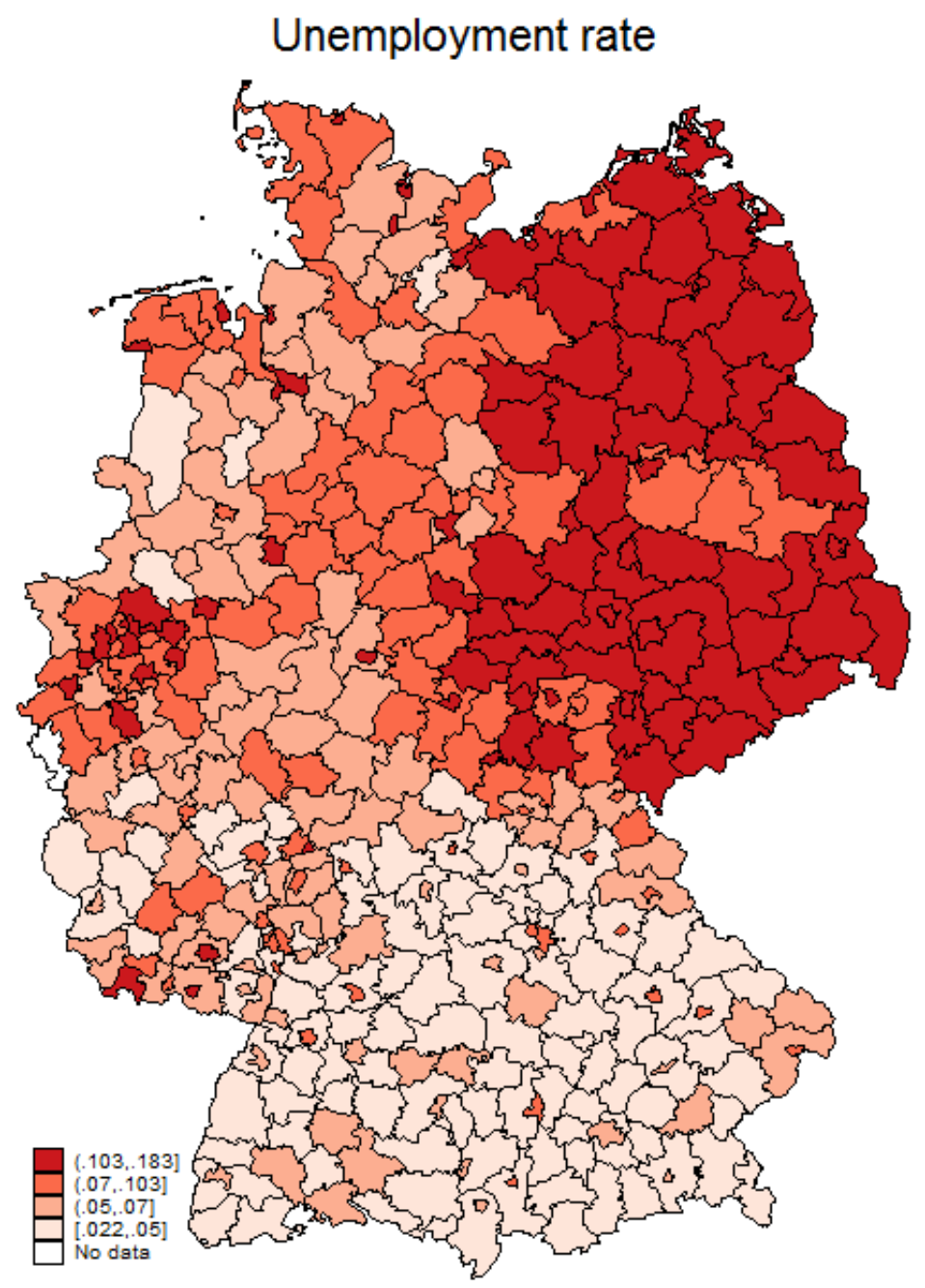


Figure A9: Effect of an increase in unemployment on assault at different quantiles

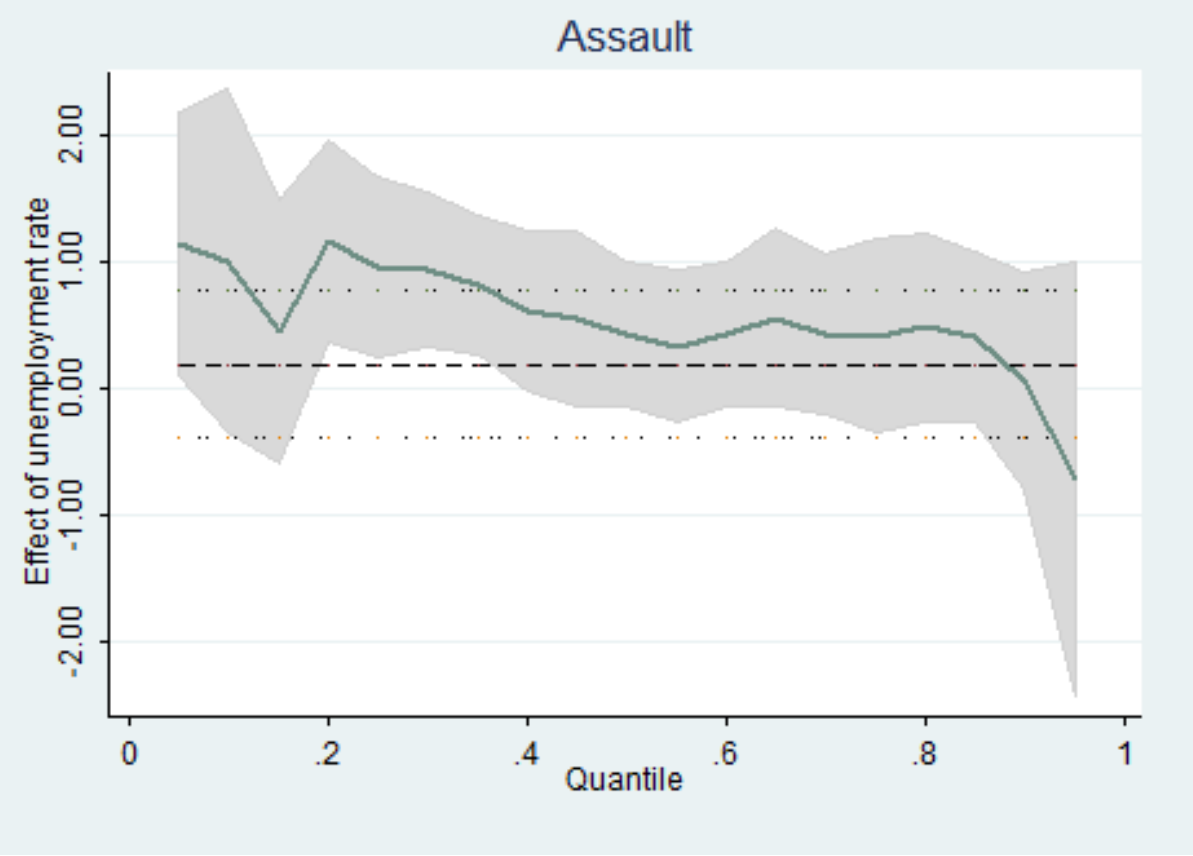

Note: This figure shows the OLS estimate of unemployment (solid dotted line) together with the $95 \%$ confidence interval (soft dotted line) and the quantile estimates (light green line) with the $95 \%$ confidence interval (grey shaded area).

Figure A10: Effect of an increase in unemployment on burglary at different quantiles

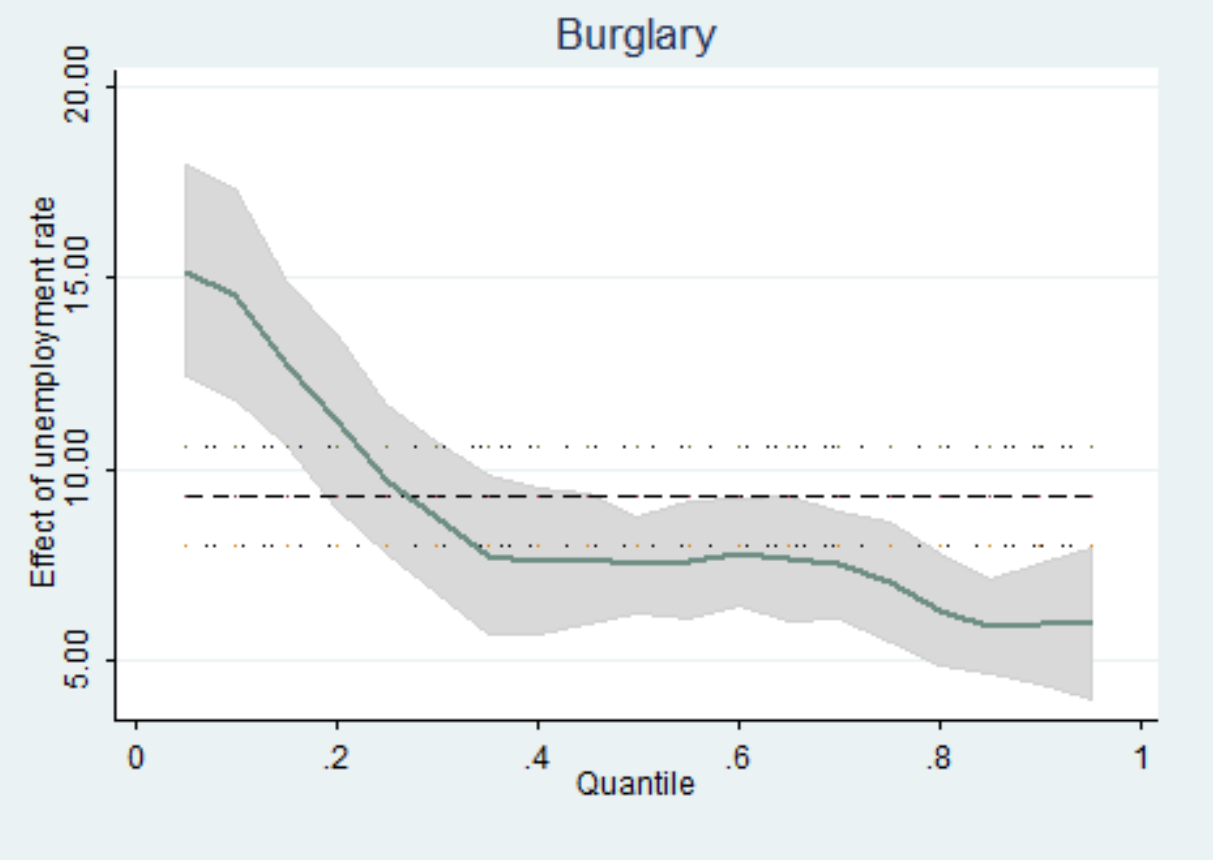

Note: This figure shows the OLS estimate of unemployment (solid dotted line) together with the $95 \%$ confidence interval (soft dotted line) and the quantile estimates (light green line) with the $95 \%$ confidence interval (grey shaded area). 
Figure A11: Effect of an increase in unemployment on auto theft at different quantiles

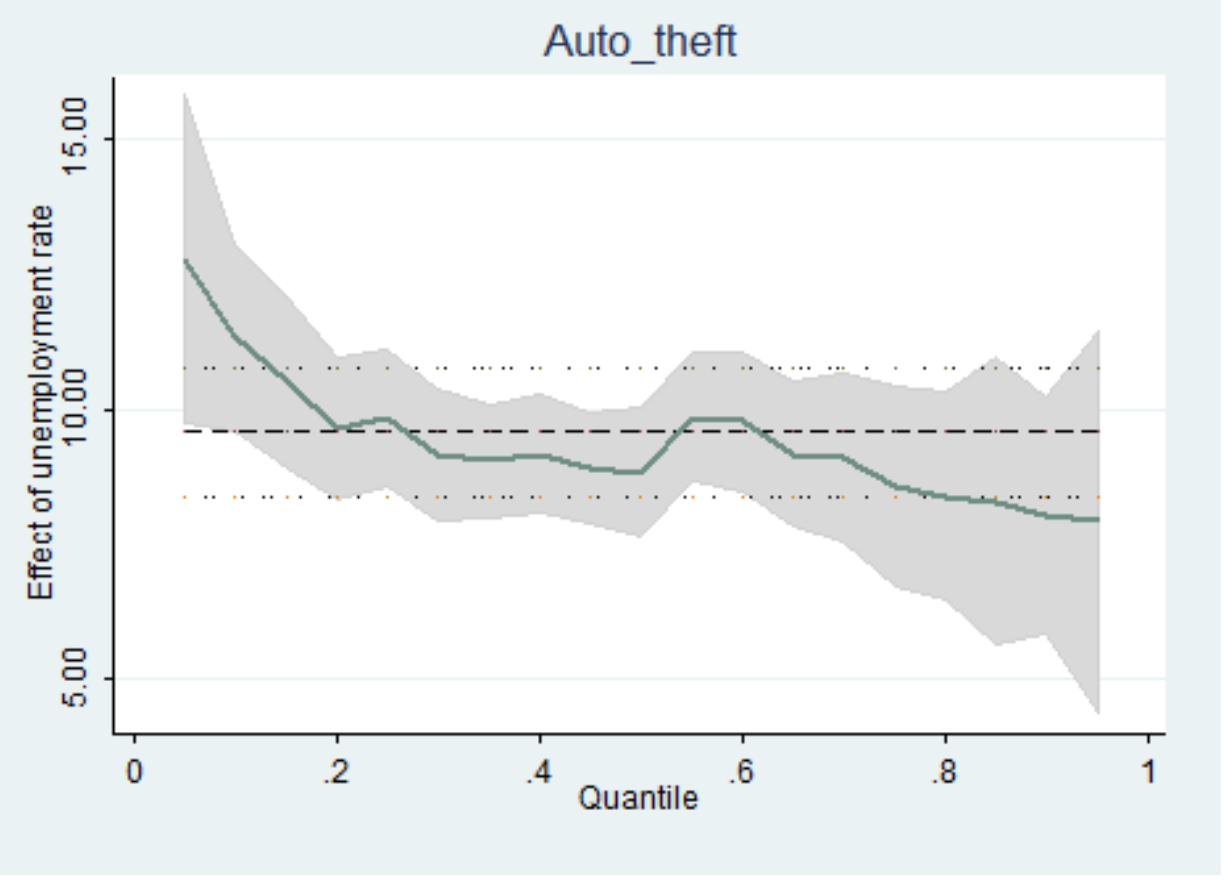

Note: This figure shows the OLS estimate of unemployment (solid dotted line) together with the $95 \%$ confidence interval (soft dotted line) and the quantile estimates (light green line) with the $95 \%$ confidence interval (grey shaded area). 


\section{References:}

Albrecht, Hans-Jörg. 1997. "Ethnic Minorities, Crime, and Criminal Justice in Germany.” Crime and Justice, 21: 31-99.

Bandyopadhyay, Siddhartha, Samrat Bhattacharya and Rudra Sensarma. 2011. An Analysis of the Factors Determining Crime in England and Wales: A Quantile Regression Approach, University of Birmingham, Discussion Paper No 11-12.

Becker, Gary. 1968. "Crime and Punishment: An Economic Approach.” Journal of Political Economy, 76(2): 169-217.

Bundeskriminalamt (Ed.): Polizeiliche Kriminalstatistik (various issues). Wiesbaden, Germany. Website: http://www.bka.de/DE/Publikationen/PolizeilicheKriminalstatistik/pks_node.html.

Cantor, David, and Kenneth C. Land. 1985. "Unemployment and Crime Rates in the Post-World War II United States: A Theoretical and Empirical Analysis.” American Sociological Review, 50(3): 317-332.

Chernozhukov, Victor, and Christian Hansen. 2008. "Instrumental variable quantile regression: A robust inference approach." Journal of Econometrics, 142(1): 379-398.

Edmark, Karin. 2005. “Unemployment and Crime: Is there a Connection?” Scandinavian Journal of Economics, 107(2): 353-373.

Ehrlich, Isaac. 1996. "Crime, Punishment, and the Market of Offenses." Journal of Economic Perspectives, 10(1): 43-67.

Entorf, Horst, and Hannes Spengler. 2000. "Socioeconomic and Demographic Factors of Crime in Germany: Evidence from Panel Data of the German States.” International Review of Law and Economics, 20(1): 75-106.

Entorf, Horst, and Hannes Spengler. 2002. "Crime in Europe.” Heidelberg and N.Y.: Springer Verlag.

Freeman, Richard B. 1996. "Why Do So Many Young American Men Commit Crimes and What Can We Do About It?" The Journal of Economic Perspectives, 10(1): 25-42.

Farrington, David P. 1986. “Age and Crime.” Crime and Justice, 7: 189-250.

Funk, P. 2004. "On the Effective Use of Stigma as a Crime-deterrent" European Economic Review, 48, 715728

Glaeser, Edward L., and Bruce Sacerdote. 1999. “Why Is There More Crime in Cities?” Journal of Political Economy, 107(6): 225-258. 
Grogger, Jeff. 1998. "Market Wages and Youth Crime.” Journal of Labor Economics, 16(4): 756-791.

Gould, Eric, Bruce Weinberg, and David Mustard. 2002. "Crime Rate and Local Labor Market Opportunities in the U.S.: 1979-1997." Review of Economics and Statistics, 84(1): 45-61.

Harding, Matthew, and Carlos Lamarche. 2009. "A quantile regression approach for estimating panel data models using instrumental variables." Economics Letters, 104(3): 133-135.

Koenker, Roger, and Kevin F. Hallock. 2001. "Quantile Regression.” The Journal of Economic Perspectives, 15(4): 143-156.

Koenker, Roger. 2004. "Quantile regression for longitudinal data.” Journal of Multivariate Analysis, 91(1): 74-89.

Lastauskas, Povilas, and Eirini Tatsi. 2013. "Spatial Nexus in Crime and Unemployment at the Dawn of Crisis: Evidence from Germany." Cambridge Working Papers in Economics 1359, Faculty of Economics, University of Cambridge.

Levitt, Steven D. 1997. "Using Electoral Cycles in Police Hiring to Estimate the Effect of Police on Crime." The American Economic Review, 87(3): 270-290.

Levitt, Steven D. 1999. "The Limited Role of Changing Age Structure in Explaining Aggregate Crime Rates." Criminology, 37(3): 581-597.

Levitt, Steven D. 2001. "Alternative Strategies for Identifying the Link between Unemployment and Crime." Journal of Quantitative Criminology, 17(4): 377-390.

Levitt, Steven D. 2004. "Understanding Why Crime Fell in the 1990s: Four Factors That Explain the Decline and Six That Do Not.” The Journal of Economic Perspectives, 18(1): 163-190.

Lin, Ming-Jen. 2008. “Does Unemployment Increase Crime?” The Journal of Human Resources, 43(2): 413436.

Messner, Steven F., Raymond H.C. Teske Jr., Robert D. Baller and Helmut Thome. 2011. "Structural Covariates of Violent Crime Rates in Germany: Exploratory Spatial Analyses of Kreise." Justice Quarterly, 30(6), 1015-1041.

Öster, Anna, and Jonas Agell. 2007. "Crime and Unemployment in Turbulent Times.” Journal of the European Economic Association, 5(4): 752-775.

R+V Versicherung-Infocenter. Website: http://www.ruv.de/de/presse/r_v_infocenter/studien/aengste-derdeutschen.jsp. 
Raphael, Steven, and Rudolf Winter-Ebmer. 2001. "Identifying the Effect of Unemployment on Crime." Journal of Law and Economics, 44(1): 259-283.

Phillips, Julie, and Kenneth C. Land. 2012. „The Link Between Unemployment and Crime Rate Fluctuations: An Analysis at the County, State and National Level." Social Science Research, 41(3): 681-694.

Sieger, Philip. 2014. “Essays in Microeconometrics: Establishing Causality in Observational Studies.” PhD Thesis, Faculty of Economics and Business Administration, Goethe University Frankfurt.

Sozialgesetzbuch (SGB) Drittes Buch (III). Website: http://www.gesetze-im-internet.de/sgb_3/

Strafgesetzbuch (StGB). Website: http://www.gesetze-im-internet.de/stgb/

Wooldridge, Jeffrey M. 2010. Econometric Analysis of Cross Section and Panel Data. Cambridge: MIT Press.

Yearwood, Douglas L. and Gerry Koinis. 2009. "Revisiting Property Crime and Economic Conditions: An Exploratory Study to Identify Predictive Indicators beyond Unemployment Rates.” MPRA Paper No. 16834.

Young, Thomas J. 1993. “Unemployment and Property Crime: Not a Simple Relationship.” American Journal of Economics and Sociology, 52(4): 413-416. 